\title{
Mechanical Properties of Cement Material for Energy-Foundation (EF) Structures
}

\author{
Yong-Boo Park ${ }^{1}$, Hangseok Choi ${ }^{2}$, Jeong-Rak Sohn ${ }^{3}$, Young-Jong $\mathrm{Sim}^{4}$ and Chulho Lee \\ (Received January 2, 2012 / Revised January 18, 2012 / Accepted January 19, 2012)
}

\begin{abstract}
In this study, physical characteristics of cement and/or concrete materials that are typically used for energy-foundation (EF) structures have been studied. The thermal conductivity and structural integrity of the cement-based materials were examined, which are commonly encountered in backfilling a vertical ground heat exchangers, cast-in-place concrete piles and concrete lining in tunnel. For this purpose the thermal conductivity and unconfined compression strength of cement-based materials with various curing conditions were experimentally estimated and compared. Hydration heat generated from massive concrete in the cast-in-place concrete energy pile was observed for 4 weeks to estimate its dissipation time in the underground. The hydration heat may mask the in-situ thermal response test (TRT) result performed in the cast-in-place concrete energy pile. It is concluded that at least two weeks are needed to dissipate the hydration heat in this case. In addition, a series of numerical analysis was performed to compare the effect of thermal property of the concrete material on the cast-in-place pile.

Keywords: Energy Foundation, Thermal Conductivity, Structural Integrity, Hydration Heat, Unconfined Compression Strength
\end{abstract}

\section{Introduction}

As hyper global issues such as depletion of fossil fuel and climatic threatening of greenhouse gas are becoming increasingly more critical, international consensuses on this problem has been considerably issued such as the Kyoto Protocol (2005) and the Copenhagen climate change conference (2009), and international demands for regulation to curb the emission of greenhouse gas is expected to become more rigorous after 2012. Among a wide variety of new and renewable energy sources, utilization of geothermal energy is a sustainable and eco-friendly energy system. According to the US Environmental Protection Agency, geothermal energy is the most efficient heating and cooling system among others. Preceding researches on geothermal energy have been mainly focused on the closed-loop vertical ground heat exchanger of which the initial construction cost is relatively high. Therefore, it is unavoidable to try to find economical alternatives to the conventional vertical ground heat exchangers in order to promote the extensive use of geothermal energy. As one of the promising options, several attempts have been made to embody heat exchange pipes in structure foundations such as piles, mat foundations, slurry walls, tunnel lining, etc. (Gao et al., 2008; Jun et al., 2009; Man et al., 2010; Nam et al., 2005; Nam and Ooka., 2011; Pahud and Hubbuck, 2007). It is of importance to identify physical properties of cement and/or concrete materials for designing the energy-foundation (so called $\mathrm{EF}$ ) structure as an infrastructure foundation system.

In this paper, the thermal conductivity of concrete materials typically used for the energy foundation (EF) structure were experimentally evaluated. In addition, the concrete strength was evaluated by performing the unconfined compression test. The concrete specimens had been exposed to periodical temperature variation to simulate a real seasonal heating-cooling operation in the energy foundation structure. Hydration heat which is generated from massive concrete in the cast-in-place concrete energy pile has been studied by performing a series of field temperature measurements of a cast-in-place concrete energy pile constructed in a test bed. The temperature monitoring lasted for four weeks to estimate the dissipation time of hydration heat in the underground. The significance of hydration heat should be considered when performing the in-situ thermal response tests (TRT's) in a castin-place concrete energy pile because the hydration heat can mask the TRT results. An example CFD numerical analysis was performed with the input parameters obtained from this

1) Research Fellow, Land \& Housing Institute (Main author: parkyb@lh.or.kr)

2) Associate Professor, School of Civil, Environmental and Architectural Engineering, Korea University (Corresponding author: hchoi2@korea.ac.kr)

3) Senior Research Fellow, Land \& Housing Institute

4) Associate Research Fellow, Land \& Housing Institute

5) Post-doctoral Research Associate, School of Civil, Environmental and Architectural Engineering, Korea University 
experimental study and literatures.

\section{Physical Properties of Cement Materials}

\subsection{Materials and Methods}

To represent the typical type of the concrete (or cement) materials used for backfilling a vertical ground heat exchanger, a cast-in-place concrete energy pile and a tunnel lining, a sample of fresh concrete mortar was taken to measure the thermal conductivity after the specimens were cured in the laboratory with different temperature conditions. The thermal conductivities of concrete specimens were measured using the QTM-500 thermal conductivity meter (Kyoto Electronics, Fig. 1 and Fig. 2) which adopts the transient hot wire method (Takegoshi et al, 1982). QTM-500 is able to make a measurement in a range of $0.023 \sim 12$ $\mathrm{W} / \mathrm{mK}$ with a reproducibility of $\pm 3 \%$. In the thermal conductivity measurement system, PD-13 probe with the dimension of $95 \mathrm{~mm}$ $\mathrm{x} 40 \mathrm{~mm}$ is used. The wet cement specimens were cured in a rectangular mold for 14 days to measure the thermal conductivity of the specimens.

The cement mixture designs considered in this paper are summarized in Table 1 and Table 2 for cement grouts of a vertical ground heat exchanger (GHEX) and for energy pile/tunnel lining, respectively. The thermal conductivities with different curing conditions (i.e., temperature and moisture content) are compared for the concrete in cast-in-place energy pile and tunnel lining.

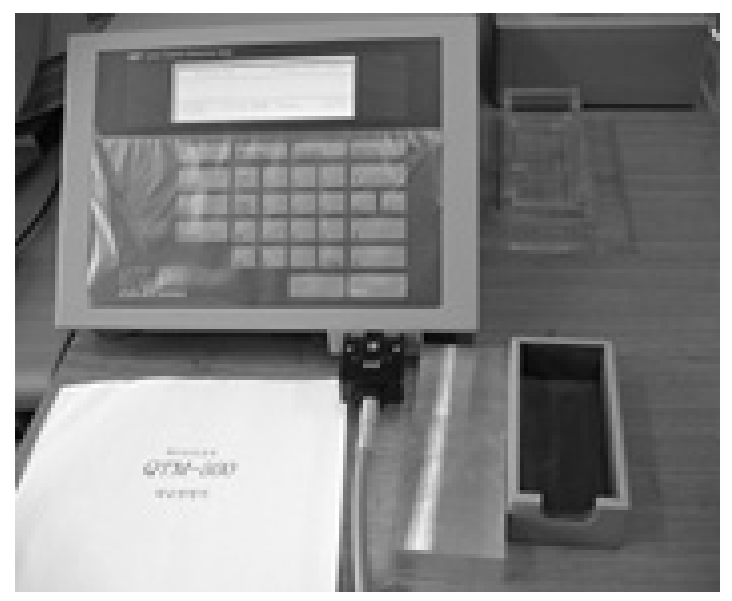

Fig. 1. QTM-500 thermal conductivity equipment

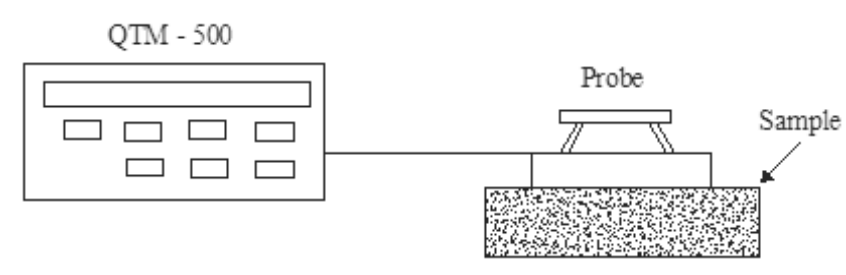

Fig. 2. Schematics of thermal conductivity measurement
In addition, the Slump flow tests were performed to evaluate the workability of cement grout for vertical ground heat exchangers. The slump flow test uses a $100 \mathrm{~mm}$-diameter mortar ring. The ring should be filled with fresh cement mortar, is put on acrylic plates, and lifted vertically. The mortar is radially spreading on the acrylic floor. The minimum and maximum diameters are then recorded. The workability of cement grout can be determined by measuring the spreading diameter. The less spreading out means lower workability.

When operating the ground heat exchanger implanted in the energy foundation (EF) structure, the strength of the energy foundation structure can be reduced due to a periodical temperature change during seasonal heating-cooling operation. Therefore, a study for the strength degradation during the repeated cycles of temperature changes is needed to assure the integrity of energy foundation structures.

In this study, the thermo-hydro static chamber was devised to apply repetitively temperature cycle between $50^{\circ} \mathrm{C}$ and $10^{\circ} \mathrm{C}$ to the concrete specimens before the strength of the concrete specimens were measured by the unconfined compression test.

Table 1. Mixture design of cement grouts for GHEX

\begin{tabular}{c|c|c|c}
\hline Specimen & $\begin{array}{c}\text { Water } \\
\text { /Cement }\end{array}$ & $\begin{array}{c}\text { Silica sand } \\
\text { /Cement }\end{array}$ & $\begin{array}{c}\text { Bentonite } \\
\text { /Cement }\end{array}$ \\
\hline GEO-1 & 0.4 & - & - \\
\hline GEO-2 & 0.5 & - & - \\
\hline GEO-3 & 0.6 & - & - \\
\hline GEO-4 & 0.7 & - & - \\
\hline GEO-5 & 0.8 & - & - \\
\hline GEO-6 & 0.6 & 2.0 & - \\
\hline GEO-7 & 0.6 & 2.2 & - \\
\hline GEO-8 & 0.6 & 2.4 & - \\
\hline GEO-9 & 0.6 & 2.6 & $1 \%$ \\
\hline GEO-10 & 0.6 & 2.8 & $2 \%$ \\
\hline GEO-11 & 0.6 & 2.4 & $3 \%$ \\
\hline GEO-12 & 0.6 & 2.4 & $4 \%$ \\
\hline GEO-13 & 0.6 & 2.4 & $6 \%$ \\
\hline GEO-14 & 0.6 & 2.4 & \\
\hline GEO-15 & 0.6 & 2.4 & - \\
\hline
\end{tabular}

Table 2. Mixture design of concrete for energy pile and Tunnel lining

\begin{tabular}{c|c|c|c|c}
\hline & $\begin{array}{c}\text { Water } \\
\left(\mathrm{kg} / \mathrm{m}^{3}\right)\end{array}$ & $\begin{array}{c}\text { Cement } \\
\left(\mathrm{kg} / \mathrm{m}^{3}\right)\end{array}$ & $\begin{array}{c}\text { Sand } \\
\left(\mathrm{kg} / \mathrm{m}^{3}\right)\end{array}$ & $\begin{array}{c}\text { Gravel } \\
\left(\mathrm{kg} / \mathrm{m}^{3}\right)\end{array}$ \\
\hline $\begin{array}{c}\text { Cast-in-place } \\
\text { energy pile }\end{array}$ & 164 & 463 & 782 & 938 \\
\hline Tunnel lining & 155 & 334 & 752 & 1047 \\
\hline
\end{tabular}




\subsection{Results}

Thermal conductivity and workability of the cement grout for vertical ground heat exchangers (GHEX's) measured in the current test program are summarized in Fig. 3. Silica sand and bentonite are usually added to decrease the density and increase the volume of cement grout. Allan and Philippacopoulos (1999) report that reducing water/cement ratio can increase the thermal conductivity of cement grout. The more water/cement ratio decreases, the more the volume of cement used in grout increases and the workability decrease. On the other hand, if the volume of cement decreases and the water/cement ratio increase, the workability increases. However, with the too large water/cement ratio, the thermal conductivity of cement grout can, in turn, dramatically decrease and the grout can be segregated.

Test specimens were made with the water/cement ratio increasing from 0.4 to 0.8 at intervals of 0.1 . The test results show that the water/cement ratio increases by 0.1 , the thermal conductivity decreases by $0.01 \sim 0.07 \mathrm{~W} / \mathrm{mK}$. The slump flow test results indicate that the workability increases with the water/cement ratio increase as shown in Fig. 3. Allan and Philippacopoulos (1999) suggested using a minimal water/cement ratio to increase the thermal conductivity and reduce the permeability of the grout. However, a significant reduction of this ratio adversely leads to the reduced workability. In addition, the thermal conductivity of the dried cement specimen is around $0.23 \sim 0.27 \mathrm{~W} / \mathrm{mK}$ which is considerably lower than that of the wet specimen.

When the water/cement ratio is fixed to 0.6 , if the silica sand/cement ratio is increased at intervals of 0.2 from 2.0 with an addition of superplasticizer by $0.1 \%$ of cement weight, the thermal conductivity increases by $0.01 \sim 0.09 \mathrm{~W} / \mathrm{mK}$. The slump flow of Geo-9 and Geo-10 specimen provide with a minimum value equal to $100 \mathrm{~mm}$. For the Geo-9 and Geo- 10 specimens, if the content of superplasticizer increases, the optimal workability is secured. The thermal conductivity decreases by about $0.20 \sim$ $0.42 \mathrm{~W} / \mathrm{mK}$ after the specimen is dried. When the water/cement and silica sand/cement ratios are fixed as 0.6 and 2.4, respectively, and the added bentonite content increases by $1 \%$ of cement

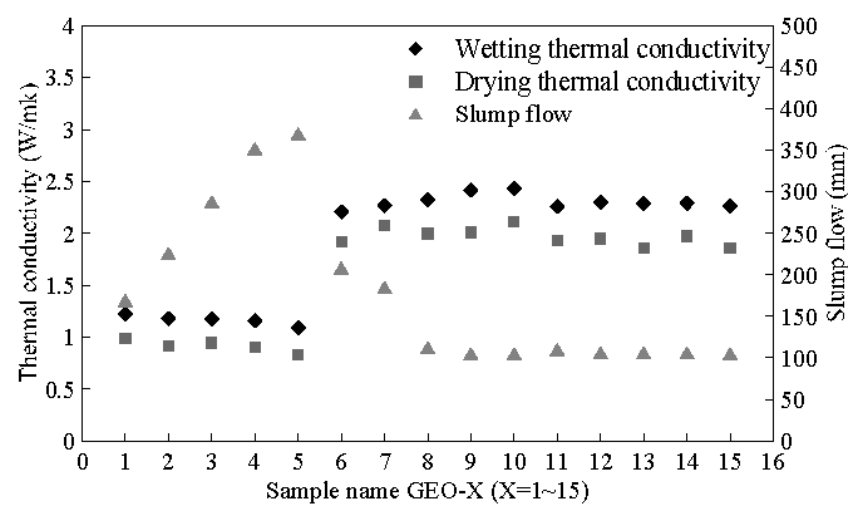

Fig. 3. Thermal conductivity and slump flow for different mixture design weight, the thermal conductivity is not significantly changed. When the specimen is air-dried, the thermal conductivity decreases by around $0.34 \sim 0.44 \mathrm{~W} / \mathrm{mK}$. In addition, if bentonite is added by $1 \%$ of cement weight, the workability of cement mortar is observed to decrease significantly.

A relationship between thermal conductivity and slump flow (i.e., workability) is illustrated in Fig. 4 after rearranging the data from Fig. 3. For the entire range of slum flow, it is surely observed that an increase in slump flow (in other words, improving workability) leads to decreasing thermal conductivity. Thus, an optimal water/cement ratio should be chosen to satisfy both the requirements of thermal conductivity and workability.

Thermal conductivity of concrete specimens of a cast-in-place energy pile and tunnel lining with different curing conditions are compared in Table 3. The concrete specimens of cast-in-place energy pile cured at a controlled temperature of $20^{\circ} \mathrm{C}$ in a water bath shows higher thermal conductivity than that cured at room temperature varying from $5^{\circ} \mathrm{C}$ to $10^{\circ} \mathrm{C}$. Thermal conductivity of concrete specimens saturated with water were obviously higher than the dry concrete specimen. As for the tunnel lining concrete, the curing condition with different temperatures was not considered but saturated specimen also shows much higher thermal conductivity than the dry specimen. Since the result presents that the thermal conductivity of the concrete varies with different curing conditions,

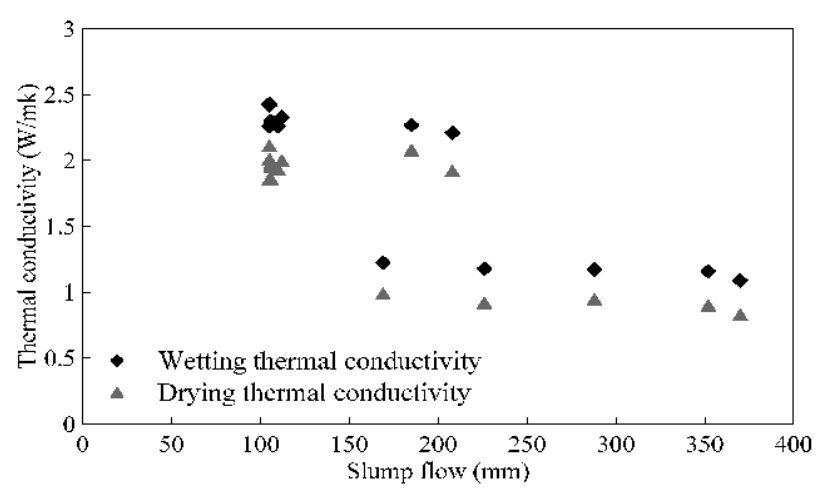

Fig. 4. Comparison between thermal conductivity and slump flow (workability) of cement grouts

Table 3. Comparison of thermal conductivity of concrete specimen with different curing conditions

\begin{tabular}{c|c|c|c}
\hline \multicolumn{2}{c|}{} & \multicolumn{2}{|c}{$\begin{array}{r}\text { Thermal conductivity } \\
(\mathrm{W} / \mathrm{m} \cdot \mathrm{K})\end{array}$} \\
\cline { 3 - 4 } & $\begin{array}{c}\text { Saturated } \\
\text { condition }\end{array}$ & $\begin{array}{c}\text { Dry } \\
\text { condition }\end{array}$ \\
\hline \multirow{2}{*}{$\begin{array}{c}\text { Cast-in-place } \\
\text { energy pile }\end{array}$} & $\begin{array}{c}\text { at room temperature } \\
\left(5 \sim 10^{\circ} \mathrm{C}\right)\end{array}$ & 2.11 & 2.02 \\
\cline { 2 - 4 } & $\begin{array}{c}\text { at controlled temperature } \\
\left(20^{\circ} \mathrm{C}\right)\end{array}$ & 2.34 & 2.18 \\
\hline Tunnel lining & $\begin{array}{r}\text { at room temperature } \\
\left(5 \sim 10^{\circ} \mathrm{C}\right)\end{array}$ & 4.30 & 3.09 \\
\hline
\end{tabular}




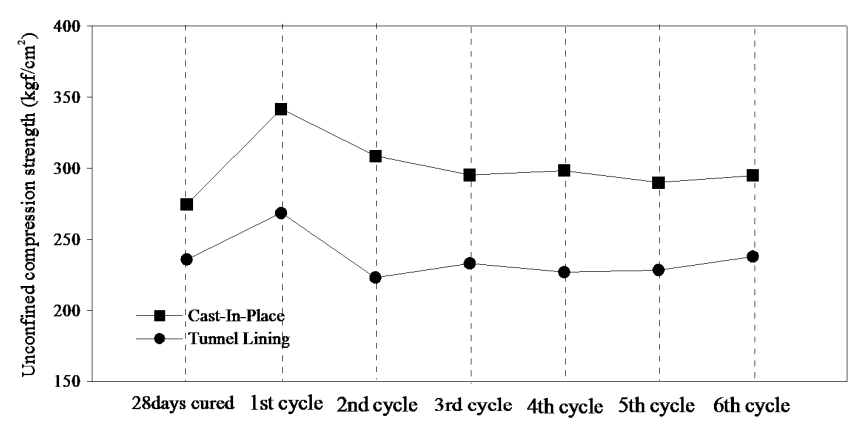

Fig. 5. Unconfined compression strength considering curing temperature cycling

the thermal conductivity of concrete specimens should be evaluated in the same curing condition as that of the field for energy foundation (EF) structures.

The unconfined compression strength of the concrete specimens was evaluated, which had been cured in the thermo-hydro static chamber by varying curing temperature between $50^{\circ} \mathrm{C}$ and $10^{\circ} \mathrm{C}$ for every 10 days. The results of the unconfined strength test were compared in Fig. 5 for specimens of cast-in-place concrete and tunnel lining concrete, respectively, which were mixed according to Table 2. The result shows that the strength of the concrete at first 10 days after 28 days curing process increases but after that, it is slightly reduced. However, the overall strength reduction is not significant after the 3rd cycle.

\section{Significance of Hydration Heat from Concrete Mass}

When a large mass of concrete solidifies in the underground which occurs at the construction of the cast-in-place concrete pile, a substantial amount of heat should be generated. Such emitting heat is called concrete hydration heat and causes the evaluation of the heat exchange rate of the energy foundation structure underestimated when performing the thermal response tests (TRT's) from the energy foundation (EF) structure. The hydration heat disguises the heat transfer from the heat exchange pipe to the ground formation during TRTs.

Hydration heat which is generated from massive concrete in the cast-in-place concrete energy pile has been studied by performing a series of field temperature measurements of a cast-in-place concrete energy pile constructed in a test bed. The temperature monitoring lasted for four weeks after the installation of the cast-in-place energy pile to estimate the dissipation time of hydration heat in the underground. The temperature distribution at the center of the pile with depth (at $3 \mathrm{~m}, 8 \mathrm{~m}, 13 \mathrm{~m}, 18 \mathrm{~m}, 23 \mathrm{~m}$, $28 \mathrm{~m}$ from the ground surface) measured by the thermocouples is plotted in Fig. 6. The hydration heat of the cast-in-place energy pile was exclusively evaluated in this paper because its mass volume is considerably large compared with that of the tunnel lining concrete. The concrete hydration heat observed during four weeks continuously decreases with time. From the temperature

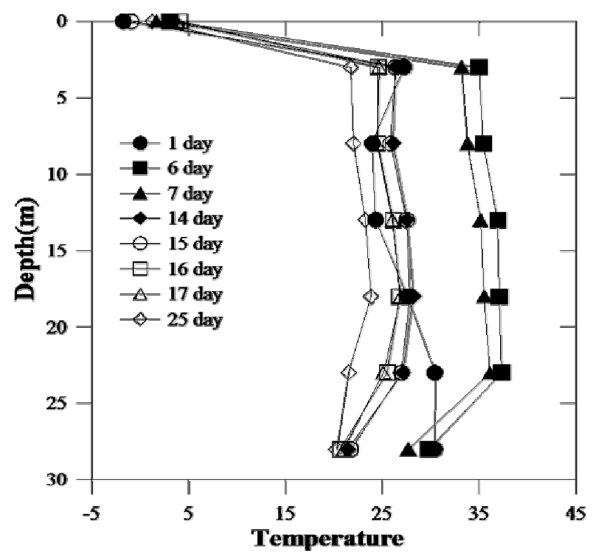

Fig. 6. Temperature distribution in a energy pile with depth

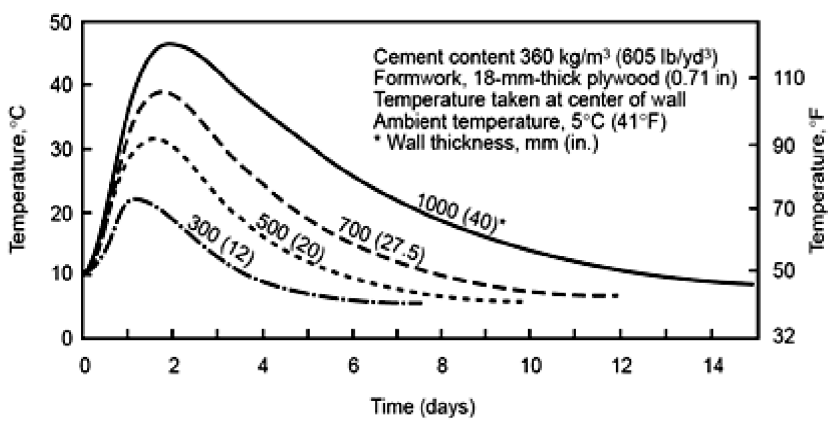

Fig. 7. Elapse of hydration heat of portland cement (PCA, 1997)

profiles shown in Fig. 6, it can be assumed that a confined aquifer is developed at around $25 \mathrm{~m}$ below the ground surface, and the groundwater flow takes away the hydration heat. In addition, it was revealed that the four-week lapse after the energy foundation structure installation was sufficient to prevent the concrete hydration heat from influencing the TRT results.

Portland Cement Association (PCA, 1997) reports that the most hydration heat of the Portland cement occurs for 3 days after cement mixing with water as shown in Fig. 7. Considering a typical diameter of borehole, 14 days will be enough for the most hydration heat dissipated. Thus, the cast-in-place energy pile needs at least 14 days elapsing after placing in the underground to perform the in-situ TRT's due to the hydration heat of cement. Before 14 days, the effective thermal conductivity by in-situ TRT's may result in underestimated value due to the additional hydration heat from cement mass.

\section{Effect of Thermal Conductivity on Energy Pile Performance}

\subsection{Numerical Simulation}

In a numerical simulation, the heat exchange pipe, cast-in-place concrete pile and surrounding ground formation were modeled using FLUENT, a finite-volume method (FVM) program, for modeling the heat transfer process of the system. For analyzing 
the solid-fluid coupled heat transfer encountered in ground heat exchangers, the mass, momentum, energy conservation of water flow, and conservation of solid are considered in the model. The modeling is based on an implicit finite volume formulation of the transient heat conduction in the three dimensional space (Yavuzturk et al. 1998).

In the numerical model, the length and diameter of an imaginary cast-in-place concrete energy pile was designed as $10 \mathrm{~m}$ and $0.4 \mathrm{~m}$, respectively. The multi-U type (two parallel U loops) heat exchange pipe arrangement was adopted. In addition, the outside and inside diameter of the heat exchange pipe were chosen as $35 \mathrm{~mm}$ and $27 \mathrm{~mm}$, respectively. The 3-D numerical model of the energy pile is illustrated in Fig. 8, which are cylindrically modeled, and Table 4 summarizes the material properties of each component modeled in the numerical analysis that were obtained from the in-situ and laboratory measurements.

The inlet boundary condition of the energy pile was designed as; a constant temperature (with $30^{\circ} \mathrm{C}$ for the cooling operation) and a constant velocity with time. The entire ground formation

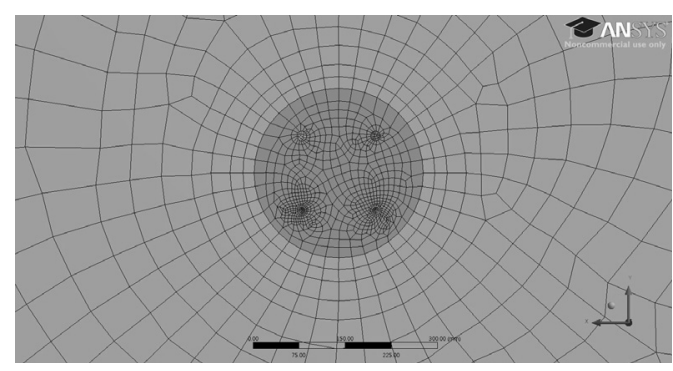

(a) Cross section of the model

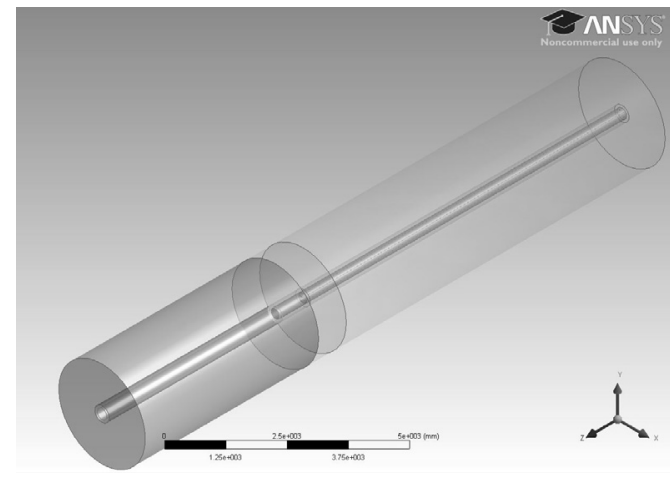

(b) 3D Numerical model configuration

Fig. 8. Numerical model configuration for energy pile

Table 4. Material properties of each component in numerical model

\begin{tabular}{c|c|c|c|c}
\hline & $\begin{array}{c}\text { Density } \\
\left(\mathrm{kg} / \mathrm{m}^{3}\right)\end{array}$ & $\begin{array}{c}\text { Specific heat } \\
(\mathrm{J} / \mathrm{kg} \cdot \mathrm{K})\end{array}$ & $\begin{array}{c}\text { Thermal } \\
\text { conductivity } \\
(\mathrm{W} / \mathrm{m} \cdot \mathrm{K})\end{array}$ & $\begin{array}{c}\text { Viscosity } \\
(\mathrm{kg} / \mathrm{m} \cdot \mathrm{s})\end{array}$ \\
\hline Water & 993.2 & 4182 & 0.6 & 0.001003 \\
\hline Concrete & 1780 & 700 & $2.02,2.34$ & - \\
\hline Pipe & 1000 & 600 & 0.5 & - \\
\hline ground & 2600 & 2500 & 3.0 & - \\
\hline
\end{tabular}

has the initial temperature of $14^{\circ} \mathrm{C}$. The temperature of the outer boundary of ground formation were also set as $14^{\circ} \mathrm{C}$. During the numerical simulation, the outlet temperature is continuously monitored and the amount of heat exchange is then calculated. Amount of heat exchange rate is evaluated to compare effects of the thermal conductivity of energy pile by applying the different thermal conductivity of concrete $(2.02$ and $2.34 \mathrm{~W} / \mathrm{mK})$ that are assumed as the upper and lower boundary values obtained form the laboratory measurement.

\subsection{Comparison of Numerical Simulation}

A typical numerical simulation result of the imaginary multi-U type energy pile is shown in Fig. 9 after 50 hours cooling mode operation (modeled with thermal conductivity of concrete is $2.02 \mathrm{~W} / \mathrm{mK})$.

The heat exchange rate for the energy pile with different thermal conductivity is compared in Fig. 10. The amount of heat exchange at 50 hours is 0.88 and $0.95 \mathrm{~kW}$ for the thermal conductivity of 2.02 and $2.34 \mathrm{~W} / \mathrm{mK}$, respectively. Because in this numerical simulation the inlet temperature was maintained

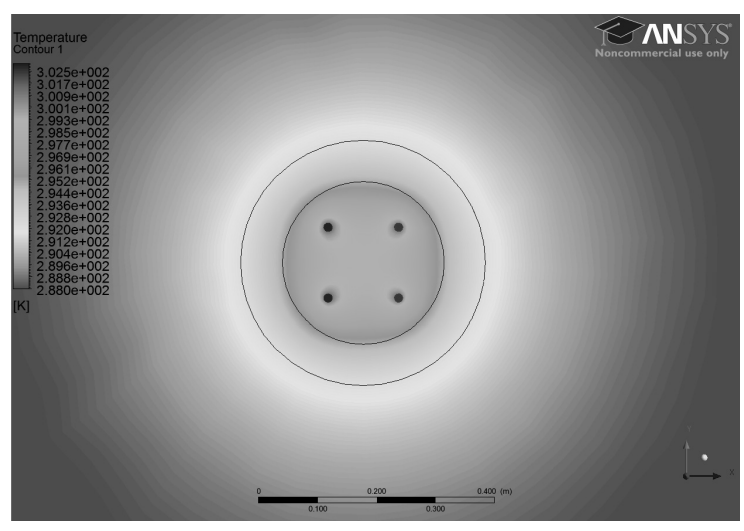

Fig. 9. Temperature distribution around modeled energy pile (after 50 hours cooling operation with $\mathrm{K}=2.02 \mathrm{~W} / \mathrm{mK}$ )

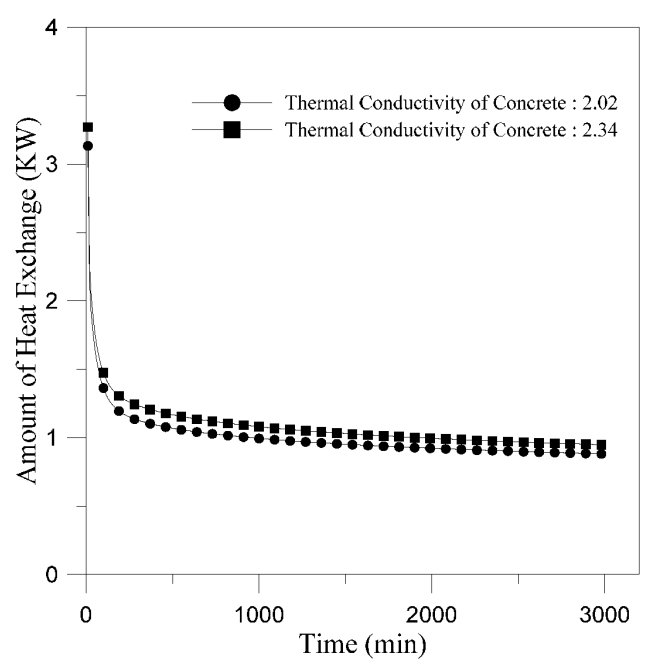

Fig. 10. Comparison of heat exchange for 50 hours cooling operation 
constant during 50 hours, the amount of heat exchange reduces with time due to increasing of ground temperature during the cooling mode. In this simulation, when thermal conductivity of concrete is $2.34 \mathrm{~W} / \mathrm{mK}$ (i.e., the upper bound thermal conductivity of concrete is used), higher heat exchange rate is obtained during 50 hours operation.

\section{Conclusions}

For use of cement materials for backfilling vertical ground heat exchanger, and the energy foundation structures, such as an energy pile and tunnel lining, the evaluation of the thermal and mechanical properties of the concrete material should be reasonably considered. The conclusions are summarized as follows:

1. Increasing the water/cement ratio can decrease the thermal conductivity of cement grout used for vertical ground heat exchangers. With the fixed water/cement, increasing the silica sand/cement ratio can increase the thermal conductivity. In the case of an addition of bentonite to the cement grout of a fixed water/cement ratio and silica sand/cement ratio, the thermal conductivity of the cement grout is almost unchanged.

2. The concrete specimens of cast-in-place pile cured at a controlled temperature of $20^{\circ} \mathrm{C}$ in a water bath shows higher thermal conductivities than those cured at room temperature varying from $5^{\circ} \mathrm{C}$ to $10^{\circ} \mathrm{C}$. The thermal conductivities of concrete specimens for the cast-in-pile energy pile and tunnel lining were obviously higher when the specimen was water-saturated than the dry concrete specimen.

3. The strength of 10 days after 28 days curing concrete was increased comparing with that of 28 days curing concrete. However, after that, the strength was gradually decreased with time. But, the overall strength reduction is not significant after the 3rd cycle.

4. The concrete hydration heat generated from the large mass of the concrete energy foundation structure was observed and continuously decreased with time. The four-week elapse after the energy foundation structure installation seems sufficient to release most hydration heat into the ground.

5. From the numerical analysis, concrete which has higher thermal conductivity shows higher amount of heat exchange. Therefore, thermally enhanced concrete or cement mixture is recommended when civil structures are used as a ground heat exchanger.

\section{References}

1. Allan, M. L. and A. J. Philippacopoulos (1999), "Properties and performance of cement-based grouts for geothermal heat pump application", U.S. Department of Energy.

2. Gao, J., X. Zhang, J. Liu, K. Li, and J. Yang (2008), "Numerical and experimental assessment of thermal performance of vertical energy pile: An application", Applied Energy, 85:901 $\sim 910$.

3. Jun, L., X. Zhang, J. Gao, and J. Yang (2009), "Evaluation of heat exchange rate of GHW in geothermal heat pump system", Renewable Energy, 34: 2898 2904.

4. Lee, C., M. Park, S. Min, H. Choi, and B. Sohn (2010), "Evaluation of performance of grouts and pipe sections for close -loop vertical ground heat exchanger by in-situ thermal response test”, Journal of Korean Geotechnical Society, 26(7): 93 106, In Korean.

5. Man, L., H. Yang, N. Diao, J. Liu, and J. Fang (2010), “A new model and analytical solutions for borehole and pile ground heat exchangers", International Journal of Heat and Mass Transfer, 53: $2593 \sim 2061$.

6. Nam, Y., R. Ooka, and S. Hwang (2005), "Development of a numerical model to predict heat exchange rate for a groune source heat pump system", Energy and Building, 40: 2113 2140 .

7. Nam, Y. and R. Ooka (2011), "Development of potential map for ground and groundwater heat pump systems and application to Tokyo", Energy and Building, 43: 677 685 .

8. Pahud, D. and M. Hubbuck (2007), "Measured thermal performances of the energy pile system of the Duck Midfield at Zurick Airport", Proceedings European Geothermal Congress, Unterhaching, Germany.

9. PCA (1997), "Portland cement, concrete and heat of hydration", Concrete Technology Today, Portland Cement Association, 18(2).

10. Takegoshi, E., S. Imura, Y. Hirasawa, and T. Takenaka (1982), "A method of measuring the thermal conductivity of solid materials by transient hot wire method of comparison", Bulletin of the Japan Society of Mechanical Engineers, 25(201): 395 402.

11. Yavuzturk, C., J. D. Spitler, and S. J. Rees (1999), “A transient two-dimensional finite volume model for simulation of vertical U-tube ground heat exchanger", ASHRAE Transactions, 105(2): $465 \sim 474$. 